\title{
Study on Coal Mine Fast Drilling Equipment and Blasting Key Technology
}

\author{
Hongli Wang ${ }^{1,2, a}$, Wei Bao ${ }^{2, b}$, Taihui $\mathrm{Xu}^{1, \mathrm{c}}$ and Lixin Song ${ }^{2, \mathrm{~d}}$ \\ 1Shandong University of Science and Technology Tai'an Campus, Tai'an, Shandong 271019, China \\ 2Shandong University of Science and Technology, Qingdao, Shandong 266590, China \\ askdwhl@163.com, bcyb7133@163.com, cskdxth@163.com, dskdkjy@163.com
}

Key words: Fast excavation, Drilling jumbo, Large-diameter, Parallel cut blasting.

Abstract. At present, in excavation of the coal mine roadway, it is widely used to a full section of millisecond blasting in borehole depth of about $2.0 \mathrm{~m}$. A lot of practice shows that, due to the influence of geological conditions, drilling, charge and other factors, footage per cycle reaching 2.5 $\sim 3.0 \mathrm{~m}$, there will be a large number of unexploded dynamite, or the low utilization rate of blasthole, which affects the driving efficiency. We need to research and develop a type of rapid composite drilling jumbo, which can drill auxiliary holes with diameter around $38 \mathrm{~mm}$, and can solve the drilling problem of large-diameter and center deep-hole of diameter not less than $120 \mathrm{~mm}$ and hole depth of about $3 \mathrm{~m}$. It matches the key blasting technology of large-diameter parallel cut blasting method, which can improve the efficiency of drilling, blasting and driving excavation.

\section{Introduction}

Drilling capacity and production efficiency of mining equipment is the main technical contradiction, they restrict the development of mining efficiency and production development in China's underground mines. At present, drilling equipments used in China some mines are mainly pneumatic drilling equipment. Although these devices has the advantages of simple structure and reliable operation, but its low drilling efficiency, poor automation \& poor working conditions, especially the poor ability of drilling deep-large hole, they can not meet the needs of large structure parameter drilling method. In recent years, a small number of large underground mine imports full hydraulic drilling jumbo from abroad. Although its has the advantages of high drilling efficiency, ability to drill deep hole and good operation conditions, but its price is expensive, complex system, difficulties of spare parts and maintenance. They are difficult to be widely applied in our country.

Therefore, we can learn from the experience at home and abroad, the development of a new type of high efficient drilling equipment has become an inevitable choice, this new equipment has the characteristics of high starting point, simple system, reliable operation, strong drilling ability, high automation, good working conditions, and it is in line with China's national conditions. New development of rapid excavation compound drilling jumbo is compared with domestic existing drill jumbo, it has the characteristics of drilling speed (for its 2 3 times) and the higher automation level. It is compared with abroad hydraulic drilling jumbo, its technology productivity can reach more than above $80 \%$, and it keeps the pneumatic drilling equipment with high reliability and convenient maintenance and low price. It is easy to be popularized and applied. At the same time, the large-diameter and parallel cut blasting technology is adopted to increase free surface of centre parallel cut blasting, improve blasting efficiency and ensure the forming effect of tunnel. In addition, the whole structure can adapt to mechanical scraping operation in the tunnel, which is conducive to eliminate slag stone and improve the efficiency of excavation[1]. 


\section{Development of rapid excavation compound drilling jumbo}

New rapid excavation compound drilling jumbo is a multifunctional drilling jumbo. It can drill small hole with diameter $38 \mathrm{~mm}$, and drill big deep hole of depth with about $3 \mathrm{~m}$ and diameter more than $120 \mathrm{~mm}$. The running mechanism of drilling jumbo adopts a small chassis track, through optimized matching, this drilling jumbo is equipped with pneumatic DTH drilling rig and fast efficient rotary impact drilling rig, and hydraulic system, electrical system, water supply system, operating system and matching drilling tools etc. (refer with Figure 1) .The lifting mechanism is composed of hinged oil cylinder and bracket, by lifting oil cylinder and control guide, it can lift within the stent, realize drilling operation with high and low different positions, different angle. DTH drill solves the drilling problems of deep hole and big hole, it can efficiently drill chisel diameter with not less than $120 \mathrm{~mm}$, the hole depth of about $3 \mathrm{~m}$, it is mainly used for drilling large diameter center cutting hole. Fast efficient rotary-impact drilling rig is a new type rig of independent research and development, it has the independent impact and independent rotary cutting and impact cutting two in one function, can rotate 360 degrees with the arm, can drill hole with around $38 \mathrm{~mm}$ diameter of arbitrary position of work face, and to compensate the positioning accuracy, not only can drill boring hole, but also can the anchor hole, roof hole, side wall hole and floor hole.

New rapid excavation compound drilling jumbo strictly implement these standards (refer with Table 1). That is JB/T9023.20-1999 of "the People's Republic of China machinery industry standard KQJ DTH drill", MT/T198-1996 of "hydraulic rock drill general technical conditions", MT/T199-1996 of "coal mine hydraulic drill rig general technical conditions", etc. And, the jumbo has obtained "the certification of coal mine safety products", and obtains 1 national invention patent and two utility model patent[2].
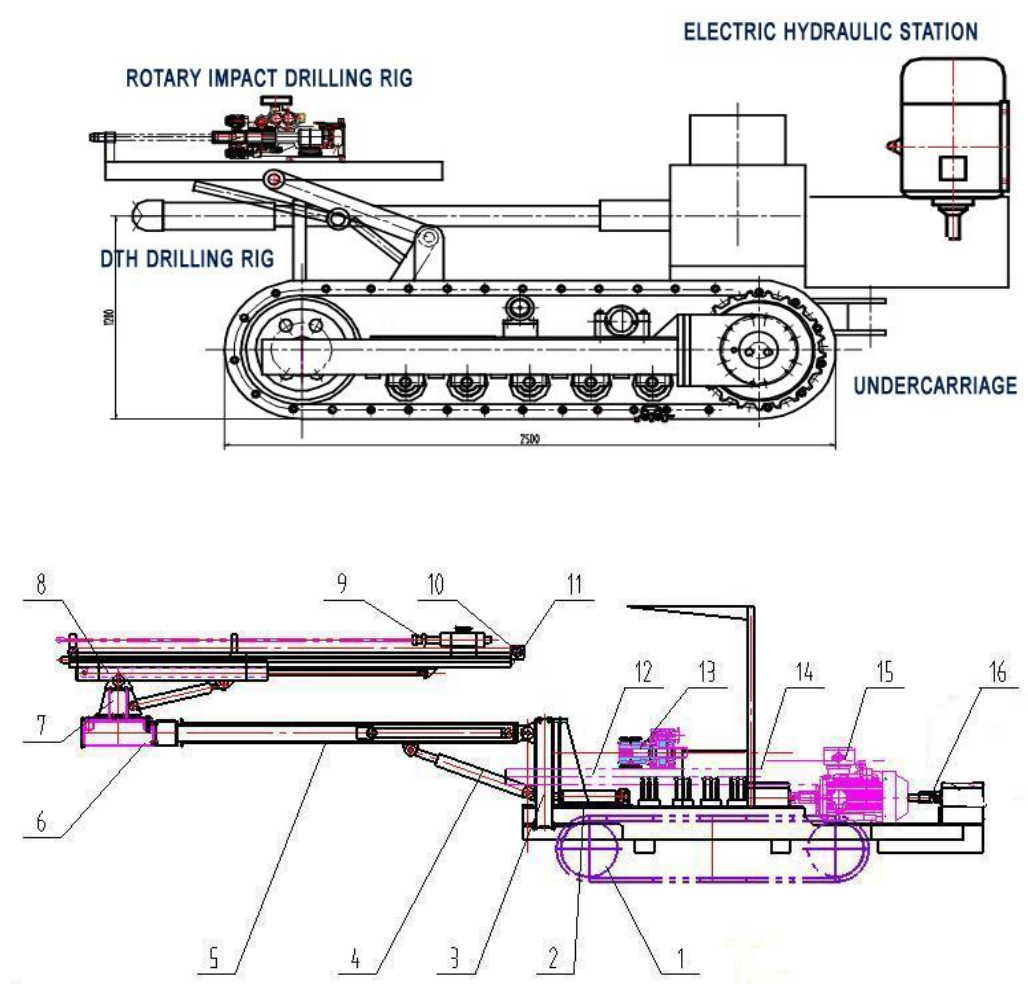

1 - track; 2 - frame; 3 - turret; 4 - cylinder; 5 - drill arm; 6, 7 - swing motor; 8 - compensation cylinder;

9 - hydraulic rock drill;10 - propulsion motor; 11 - hydraulic rock drill way; 12 - DTH drill way;

13 - DTH drill rotating department; 14 - DTH drill to promote department; 15 - electrical system; 16 - hydraulic system.

Figure 1. Structure chart of rapid excavation compound drilling jumbo 
Table 1. Technical parameters of rapid excavation compound drilling jumbo

\begin{tabular}{|c|c|c|c|}
\hline Name & Item & Unit & Parameter \\
\hline \multirow{9}{*}{ Overall machine } & Overall size $(\mathrm{L} \times \mathrm{w} \times \mathrm{h})$ & $\mathrm{mm}$ & $9500 \times 1100 \times 3500$ \\
\hline & Caterpillar climbing ability & $\circ$ & $\geq 25^{\circ}$ \\
\hline & Walking speed & $\mathrm{km} / \mathrm{h}$ & $0 \sim 2.4$ \\
\hline & Power supply voltage & $\mathrm{V}$ & $380 / 660$ \\
\hline & Power & $\mathrm{kW}$ & 31 \\
\hline & Drill arm number & & 2 \\
\hline & Hardness of rock & & $\mathrm{f} 6 \sim \mathrm{f} 14$ \\
\hline & Drill pipe length & $\mathrm{m}$ & $2.5 \sim 3.0$ \\
\hline & Gross weight & $\mathrm{t}$ & 5.5 \\
\hline \multirow{7}{*}{$\begin{array}{c}\text { Fast efficient } \\
\text { rotary impact } \\
\text { drilling rig }\end{array}$} & Impact work & $\mathrm{J}$ & $60 \sim 65$ \\
\hline & Impact frequency & $\mathrm{Hz}$ & $55 \sim 60$ \\
\hline & Torque & $\mathrm{kN} \cdot \mathrm{m}$ & $60 \sim 65$ \\
\hline & Speed & $\mathrm{r} / \mathrm{min}$ & $250 \sim 300$ \\
\hline & Gas water discharge capacity & $\mathrm{kg}$ & $5-8 / 3-5$ \\
\hline & Oil pressure & $\mathrm{MPa}$ & 17 \\
\hline & Borehole diameter & $\mathrm{mm}$ & $32 \sim 46$ \\
\hline \multirow{7}{*}{$\begin{array}{c}\text { Pneumatic DTH } \\
\text { drilling rig }\end{array}$} & Borehole diameter & $\mathrm{mm}$ & $\geq 120$ \\
\hline & Impact work & $\mathrm{J}$ & 170 \\
\hline & Impact frequency & $\mathrm{Hz}$ & 23 \\
\hline & Gas consumption & $\mathrm{m}^{3} / \mathrm{min}$ & $6 \sim 8$ \\
\hline & Wind pressure & $\mathrm{MPa}$ & $0.5 \sim 1$ \\
\hline & Speed & $\mathrm{r} / \mathrm{min}$ & $70 \sim 120$ \\
\hline & Torque & $\mathrm{N} \cdot \mathrm{m}$ & $150 \sim 200$ \\
\hline
\end{tabular}

\section{Technology of large-diameter parallel cut blasting}

When medium-deep parallel cut blasting, the key to improve the blasting efficiency is to determine the correct blasting parameters and select the reasonable cutting pattern. There are a lot of ways to parallel cut blasting, the rock will be completely broken in the cavity without leaving residual hole, and the broken rock will be completely thrown out of the cavity, this is a more successful method of cutting, thus the broken rock can be completely thrown out of the cavity, to avoid broken rock regeneration or re consolidation, it can also provide free surface and large expansion space for blasting hole behind. In order to achieve the best effect, we should optimize the design of the hole, the charge structure and the firing sequence. According to many years of construction experience and optimization of blasting parameters, the chart of blasthole layout (refer with Figure 2) is used[3].

As shown in figure 2, the hole location is arranged in the section of the roadway. The rapid excavation compound drilling jumbo are arranged in the working head-on face. Drilling auxiliary hole with diameter about $38 \mathrm{~mm}$. At the same time, DTH Drill rig drills two center hole with depth of about $3 \mathrm{~m} \&$ diameter more than $120 \mathrm{~mm}$.

According to the design of tunnel blasting, we design the tunnel blasting chart (refer with Table 2), this table includes layout chart of borehole, design table of borehole parameters and table of the expected effect of blasting. Among them: according to the traditional concept, we design auxiliary hole, two circle hole, floor hole \& surrounding hole, such as borehole layout. The design of 
cutting-hole is a blasting method of large-diameter cutting hole, that is, in the middle of the roadway section or near the middle position, the two large-diameter parallel cut holes of more than diameter $120 \mathrm{~mm}$ without filling explosive are arranged. Within diameter $1.4 \sim 1.5 \mathrm{~m}$ scope around the large-diameter hole, we arrange 8 ordinary explosive holes with diameter about $38 \mathrm{~mm}$. The depth of large-diameter parallel cut hole should be more deeper $300 \mathrm{~mm}$ than the depth of small-diameter explosive hole. And at the bottom of each large-diameter parallel cut hole, we fill with $1.5 \mathrm{~kg}$ explosive[4].

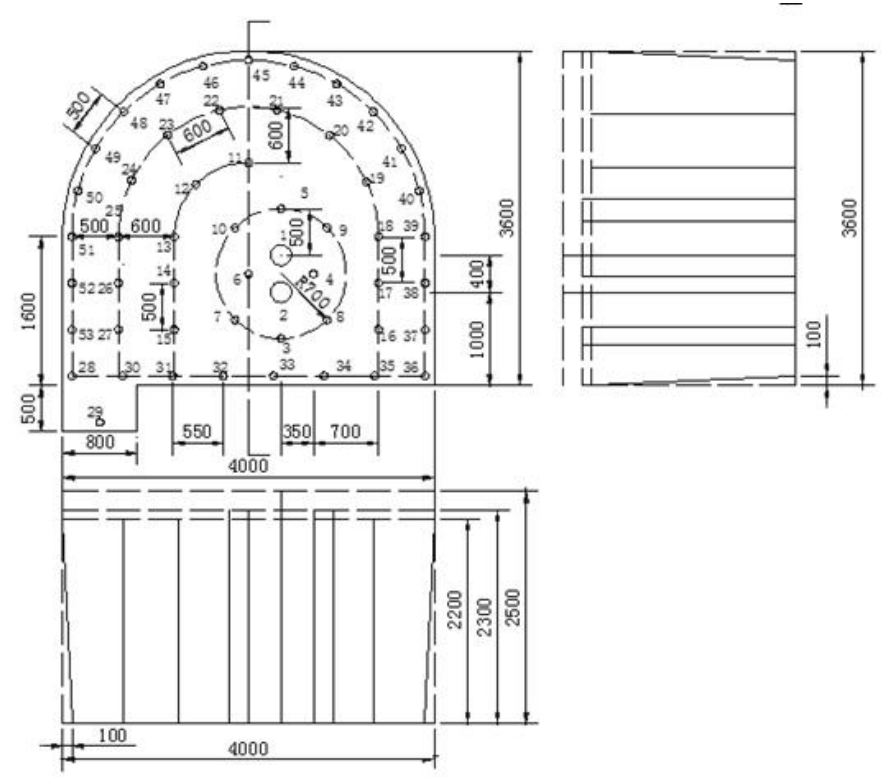

Figure 2. Design chart of blasting hole arrangement of the tunnel

The design of blasting sequence is as follows. First of all, the 8 small-diameter cut holes around the large-diameter parallel cut hole start blasting. The second step, explosive bag in the bottom of large-diameter parallel cut hole start blasting. The third step, from the cutting hole outward, we start blasting explosives from the auxiliary hole to the hole of second circle in proper order. The fourth step, we start blasting explosives of floor hole and surrounding hole. The blasting parameters are shown as (refer with Table 2)[5].

Table 2. Blasting parameters

\begin{tabular}{|c|c|c|c|c|c|c|c|}
\hline \multirow{2}{*}{$\begin{array}{c}\text { Name of blasting } \\
\text { hole }\end{array}$} & \multirow{2}{*}{$\begin{array}{l}\text { Number of } \\
\text { blasting hole }\end{array}$} & \multirow{2}{*}{$\begin{array}{c}\text { Angle } \\
1^{\circ}\end{array}$} & \multicolumn{3}{|c|}{ Explosive charge $/ \mathrm{kg}$} & \multirow{2}{*}{$\begin{array}{l}\text { Blasting } \\
\text { sequence }\end{array}$} & \multirow{2}{*}{$\begin{array}{l}\text { Connection } \\
\text { mode }\end{array}$} \\
\hline & & & $\begin{array}{l}\text { Each } \\
\text { hole }\end{array}$ & $\begin{array}{l}\text { Number } \\
\text { of holes }\end{array}$ & Total & & \\
\hline Middle empty hole & $1 、 2$ & 90 & & & & & \\
\hline Empty hole bottom & $1 、 2$ & 90 & 1.5 & 2 & 3.0 & 2 & \multirow{7}{*}{$\begin{array}{c}\text { Series } \\
\text { connection }\end{array}$} \\
\hline Main cutting hole & $3-6$ & 90 & 0.9 & 4 & 3.6 & 1 & \\
\hline Side cutting hole & $7-10$ & 90 & 0.9 & 4 & 3.6 & 1 & \\
\hline Auxiliary hole & $11-15$ & 90 & 0.75 & 5 & 3.75 & 3 & \\
\hline Hole of second circle & $16-27$ & 90 & 0.6 & 12 & 7.2 & 4 & \\
\hline Floor hole & $28-36$ & 90 & 0.75 & 9 & 6.75 & 5 & \\
\hline Surrounding hole & $37-53$ & 89 & 0.45 & 17 & 7.65 & 5 & \\
\hline Summation & & & & 53 & 35.55 & & \\
\hline
\end{tabular}




\section{Conclusions}

(1) From the point of construction technology, the rapid excavation compound drilling jumbo can be formed larger blasting free surface by mechanical way( two hole of diameter 120 $\mathrm{mm}$ above ). The same diameter of the cutting hole is compared with the original empty hole, which can provide greater compensation space, and to meet the requirements of rock burst in cutting hole, to provide more favorable free surface for cutting blasting. Fast efficient rotary-impact drilling rig can be freely drilling hole with $360^{\circ}$ angle and different height. And it can be drilling borehole closer to wall to the maximum extent, which completely solves the difficult to cutting hole, low of hole utilization rate, serious damage of surrounding rock and other problems.

(2) The depth of hollow hole is at least deeper 300mm than the depth of cutting hole , to provide space for filling with explosive bag for throwing slag. At the same time, electronic digital detonator has been able to achieve an accurate delay of $15 \mathrm{~ms}$, which can eliminate the passivation effect, and to fully guarantee the reliable initiation of explosive bag for throwing slag, to form a good effect of polishing slag, and to create the conditions for the formation of good explosion cavity. At the same time, cutting blasting use only a section of detonator, and to create conditions for realizing caving and surrounding hole 50ms delay. The middle-deep hole blasting is realized in mine roadway excavating.

(3) Due to enough compensation space from the large-diameter hollow hole, the depth of cutting hole does not need to be deepened, using the same depth as other holes, which is easy to operate. At the same time, the number of holes can be reduced properly. The formation of good cavity can effectively reduce the number of caving hole and the unit consumption of explosives . It can greatly reduce the total length per metre of each cycle and consumption of explosives and detonators. The driving speed is improved and the cost is reduced.

In the coal mine tunneling operation, we use this drilling jumbo and blasting technology, which can effectively improve the blasting effect of tunnel excavation, to improve the hole utilization rate of each cyclicfootage (it can be increased to more than $90 \%$ ), to reduce the number of holes per cycle (reduced 5 10 holes) and the consumption of detonators, to reduce the unit consumption of explosives (explosive consumption can reduce more than $0.2 \mathrm{~kg} / \mathrm{m}^{3}$ ). The middle-deep hole blasting is realized to improve the tunneling speed greatly.

\section{Acknowledgements}

This work was financially supported by Shandong Province Science and Technology Development Program (2013GSF12002) and Qingdao Cultivation Program of Medium-small Sized Innovative Enterprises (13-1-4-35-gx).

\section{References}

[1] Wei Bao, Lixin Song, Jinqiao Zhao: Coal Mine Machinery, Vol.8(2015), p.202(in Chinese)

[2] Zilong Shi, Hongbin Wang, Shiyi Wang: Mine Construction Technology, Vol.6(2009), p.35(in Chinese)

[3] Yan Zhao. Qinhuangdao: Yanshan University, 2010(in Chinese)

[4] Congyin Wang: Blasting, Vol.2(1995), p.51(in Chinese)

[5] Hongli Wang, Jinqiao Zhao, Wei Bao: Mining Machinery,Vol.21(2008), p.6(in Chinese) 